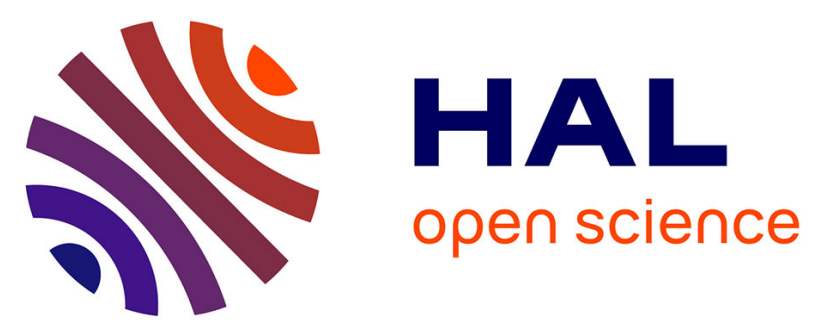

\title{
Combining scintillometer measurements and an aggregation scheme to estimate area-averaged latent heat flux during the AMMA Experiment
}

J. Ezzahar, Ghani Chehbouni, Joost Hoedjes, D. Ramier, Nicolas Boulain, S. Boudkraoui, Bernard Cappelaere, L. Descroix, Bernard Mougenot, Franck Timouk

\section{To cite this version:}

J. Ezzahar, Ghani Chehbouni, Joost Hoedjes, D. Ramier, Nicolas Boulain, et al.. Combining scintillometer measurements and an aggregation scheme to estimate area-averaged latent heat flux during the AMMA Experiment. Journal of Hydrology, 2009, 375 (1-2), pp.1-10. 10.1016/j.hydrol.2009.01.010 . ird-00389812

\section{HAL Id: ird-00389812 https://hal.ird.fr/ird-00389812}

Submitted on 4 Jun 2009

HAL is a multi-disciplinary open access archive for the deposit and dissemination of scientific research documents, whether they are published or not. The documents may come from teaching and research institutions in France or abroad, or from public or private research centers.
L'archive ouverte pluridisciplinaire HAL, est destinée au dépôt et à la diffusion de documents scientifiques de niveau recherche, publiés ou non, émanant des établissements d'enseignement et de recherche français ou étrangers, des laboratoires publics ou privés. 


\title{
Combining scintillometer measurements and an aggregation scheme to estimate area-averaged latent heat flux during the AMMA experiment
}

\author{
J. Ezzahar ${ }^{\mathrm{a}}$, A. Chehbouni ${ }^{\mathrm{b}, *}$, J. Hoedjes $^{\mathrm{b}}$, D. Ramier ${ }^{\mathrm{c}}$, N. Boulain ${ }^{\mathrm{d}}$, S. Boubkraoui ${ }^{\mathrm{c}}$, B. Cappelaere ${ }^{\mathrm{d}}$, \\ L. Descroix ${ }^{c}$, B. Mougenot ${ }^{b}$, F. Timouk ${ }^{b}$
}

${ }^{a}$ Faculty of Sciences and Technology, Caddi Ayyad University, Marrakech, Morocco

${ }^{b}$ Centre d'Etudes Spatiales de la Biosphère (CESBIO/IRD), 18 Avenue Edouard belin, 31401 Toulouse Cedex 9, France

8 Q1 ' $I R D$, Centre Niamey, Niger

$9 \quad{ }^{\mathrm{d}}$ HSM, Montpellier, France

\section{A R T I C L E I N F O}

Article history:

Available online $\mathrm{xxxx}$

\section{Keywords:}

Scintillometry

Eddy covariance

Regional surfaces fluxes

Non-uniform and heterogeneous surfaces

Aggregation schemes

\section{S U M M A R Y}

This paper deals with the issue of using scintillometry in conjunction with a simple aggregation scheme to derive area-averaged sensible and latent heat fluxes over a small watershed in Niamey, Niger (Wankama catchment). Data collected in the context of the African Monsoon Multidisciplinary Analysis (AMMA) program has been used to test the proposed approach. For this purpose, a Large Aperture Scintillometer (LAS) was set up over heterogeneous surface transect of about $3.2 \mathrm{~km}$ spanning three vegetation types.

The comparison between scintillometer-based estimates of area-averaged sensible heat fluxes and those measured by a network of the classical eddy covariance (EC) devices showed good agreement, with a relative error of about $20 \%\left(R^{2}=0.85, \mathrm{RMSD}=22 \mathrm{~W} \mathrm{~m}^{-2}\right.$, and SEE $\left.=21.39 \mathrm{~W} \mathrm{~m}^{-2}\right)$. This is a good result

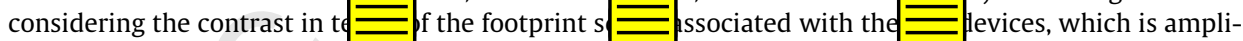
fied by the heterogeneity of 1 :hment. The res area-average sensible heat flux in conjunction with a simple aggregation rule to estimate area-average available energy led to a reasonable prediction of area-averaged latent heat flux $\left(R^{2}=0.75\right.$, RMSD $=64 \mathrm{~W} \mathrm{~m}^{-2}$ and SEE $=50 \mathrm{~W} \mathrm{~m}^{-2}$ ), when compared to those measured using the EC net -2 his is of intere -2 the LAS can $\ldots$ ally be used to validate estimates of surface fluxes, ba: meso-scale , as well as th

\section{Introduction}

The West African region has been undergoing tremendous changes over the last 30 years. The Sahel is prone to extremes in climate variability, with persistent drought which causes recurrent famine and humanitarian crises. It is thus of crucial importance to develop a clear understanding and accurate methods for predicting the combined effect of both human- and nature-induced changes on water resources so that decision makers can develop mitigating strategies based on solid science.

In this context, several large-scale field experiments such as the Hydrologic and Atmospheric Pilot Experiment in the Sahel (Goutorbe et al., 1994) and the African Monsoon Multidisciplinary Analysis (AMMA: http://www.amma-international.org) were con-

\footnotetext{
* Corresponding author. Tel.: +33 (0)5 6155 8197; fax: +33 (0)5 61558500 .

E-mail addresses: j.ezzahar@ucam.ac.ma (J. Ezzahar), ghani@cesbio.cnes.fr, Ghani.Chehbouni@ird.fr(A.Chehbouni), ramier@ird.ne (D. Ramier), boulain@msem. univ-montp2.fr (N. Boulain), stephane.boubkraoui@ird.ne (S. Boubkraoui), bernard. cappelaere@msem.univ-montp2.fr (B. Cappelaere), descroix@ird.ne (L. Descroix), mougenot@cesbio.cnes.fr (B. Mougenot), franck.timouk@cesbio.cnes.fr (F. Timouk).
}

ducted over this region in recent years. These studies have substantially advanced the understanding of the interaction between regional climate and the hydrological cycle.

Among the surface processes of prime importance in addressing the issue of the interaction of surface conditions and climate processes is the evapotranspiration or latent heat flux density (LE), which is essential in bringing together analyses of the physical, biological, and hydrological processes occurring at different space-time scales over continental surfaces. This same process describes the transport of water into the atmosphere from surfaces, through soil evaporation and plant transpiration.

Additionally, understanding the spatial distribution of LE is essential for many environmental applications including water resources management, agriculture efficiency, global vegetation analysis, climate dynamics, and ecological applications. Consequently, the AMMA program put a strong emphasis on the challenging task of modeling and measurement of LE at different ranges of the space-time scale. The surface heterogeneity caused by the contrast in vegetation cover and type-and/or by precipitation-generates a large spatial variability of surface fluxes. Therefore, estimating LE under such conditions is not an easy task. 


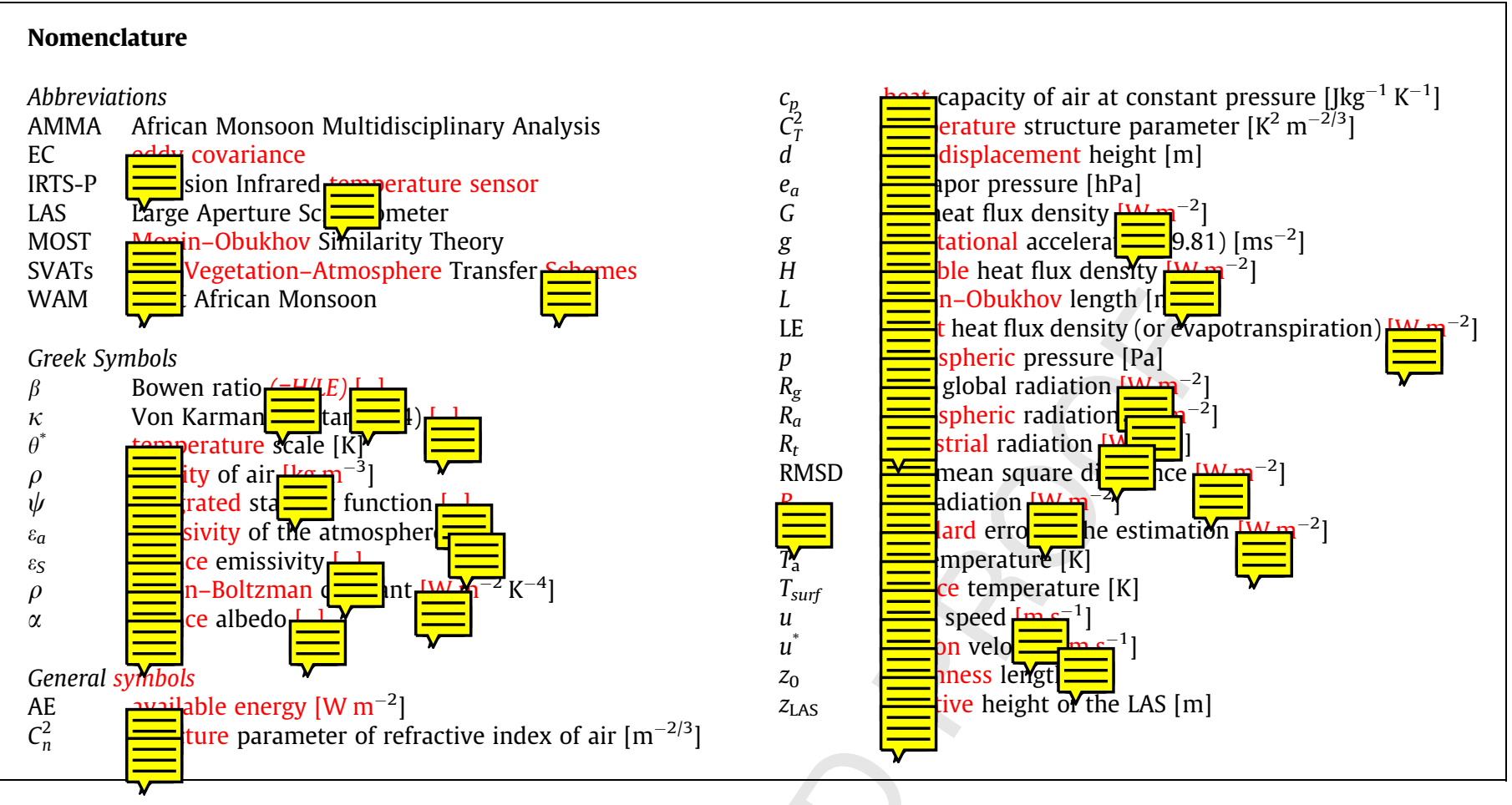

Numerous Soil-Vegetation-Atmosphere Transfer schemes (SVATs) have b veloped with varying degrees of complexity, and many are ( $=$ ed to use remote sensing data to provide an area-averaged LE (Allen et al., 2007; Bastiaanseen et al., 1998; Caparrini et al., 2003, 2004; Cleugh et al., 2007; Crow and Kustas, 2005; French et al., 2005; Moran et al., 1994; Mu et al., 2007; Norman et al., 2003; Schmugge et al., 1998; Su, 2002; Timmermans et al., 2007; Zhan et al., 1996). However, one of the main difficulties faced in developing these regional heat fluxes concerns the evaluation of their outputs against ground observations. In most of the micrometeorological studies, a network of point-sampling devices-such as the EC system-is used. However, due to their high price and the requirement for the continuous availability of welltrained staff to operate and maintain them, these devices might not be the best choice for obtaining the area-average of LE, especially in remote areas. Such limitations lead the scientific community to look for alternative techniques to estimate the area-average of LE over heterogeneous surfaces.

Recent studies have shown that scintillometry offers a useful alternative method for routine measurements of area-average of the sensible heat flux density $(H)$, and thus LE (Chehbouni et al., 1999, 2000a, in press; Ezzaha -, 2007a; Hemakumara et al., 2003; Meijni $\mathrm{t}$ al., $2002 \equiv$ 6). In most of these studies, Large Apertur $\equiv$ tillometers (LAS) were used, which allow measurements over path lengths of up to $5 \mathrm{~km}$. Recently, this instrument has become very popular especially because, in contrast to the network of EC systems, it requires relatively little maintenance and is therefore cost effective. The LAS provides a measurement of the structure parameter for the refractive index $\left(C_{n}^{2}\right)$, which can be related to the structure parameter of temperatur $\mathrm{s}$ derive sensible heat flux $\left(H_{\text {LAS }}\right)$ through the application $\mathrm{c} \equiv$ in-Obukhov Similarity Thec OST). It should be mentioned that the use of LAS over hete. $=$ ous surfaces to estimate path-average $H$ is subject to the applicability of MOST theory under such conditions. Fortunately, the study performed in Ezzahar et al. (2007b) showed that MOST scaling function also holds over heterogeneous surfaces (tall and sparse vegetation). This study-as well as that of Chehbouni et al. (in press)-also shows that there is a layer below the so- called "blending height" where MOST still holds true. This is of practical interest since it is not always feasible to install the LAS in stable conditions on high towers (e.g. on platforms above the blending height).

It is thus feasible to use the LAS for operationally estimating area-average LE as the residual term of the energy balance equation providing estimates of area-average available energy $\left(\mathrm{AE}=R_{n}-G\right)$, where $\left(R_{n}\right)$ is the net radiation and $(G)$ is the soil heat flux. Here again, are age AE can be constru y deploying a network of net ra which is also costly and really $n, \ldots$ icularly feasible. An aggre tion scheme for estimating areã surface temperature, albedo, incoming radiation and other ancillary meteorological data is therefore needed in order to estimate area-average LE through the combination of the LAS measurements and the energy balance equation.

In this regard, substantial efforts have been made in the development of the aggregation scheme to estimate area-average surfaces fluxes over heterogeneous surfaces (Koster and Suárez, 1992; Sellers et al., 1997; Noilhan and Lacarrere, 1995; Arain et al., 1996; Noilhan et al., 1997; Raupach and Finnigan, 1995; Lhomme et al., 1994; Chehbouni et al., 1995, 2000b, 2008). The aggregation scheme is conceived as a method which st link the model parameters which control surface exchang $\equiv$, atch scale with the area-average value of equivalent model parameters applicable at larger scale or grid scale, assuming that the same equations are used to describe surface fluxes at both scales.

The present study is specifically devoted to the investigation of whether the combination of the LAS and a simple aggregation scheme for estimating area-averaged available energy can provide reasonable estimates of area-average LE over a heterogeneous catchment. This has been undertaken in the framework of the international AMMA program, which aims to improve our knowledge and understanding of the West African Monsoon (WAM) and its variability.

This paper is organized as follows: "Theory" presents the theoretical background used to estimate tl $-\rho$ - 1-average LE; "Experimental site and measurements" di $\equiv$ s the site " 
experimental setup; "Resillts and discussion" presents the results of the comparison be the measured and estimated area-averaged surface fluxes; finally, "Conclusions and perspectives" provides a discussion and concluc

\section{Theory}

\section{Determination of the turbulent heat fluxes with the LAS}

The LAS is a device that provides measurements of the variation in the refractive index of air caused by atmospheric turbulence. This instrument consists of a transmitter and a receiver, both with an aperture diameter of $0.15 \mathrm{~m}$, set up at a separation distance (or path length) ranging from 250 to $5000 \mathrm{~m}$. The transmitter emits electromagnetic radiation, which is scattered by the turbulent atmosphere, and the resulting variations in signal intensity (scintillations) are recorded by a receiver comprising an identical mirror and a photodiode detector. The intensity fluctuations are related to the path-averaged structure parameter of the refractive index of air, $C_{n}^{2}$. For the scintillometers operating at near-infrared wavelength, Wesely (1976) and, more recently, Moene (2003) demonstrate that $C_{n}^{2}$ is related to $C_{T}^{2}$, the structure parameter of temperature, as

$C_{T}^{2}=C_{n}^{2}\left(\frac{T_{a}^{2}}{-0.78 \times 10^{-6} p}\right)^{2}\left(1+\frac{0.03}{\beta}\right)^{-2}$

where $T_{a}$ is the air temperature, $p$ is atmospheric pressure and $\beta$ is the Bowen ratio. The factor involving the Bowen ratio is the correction term for the influence of humidity fluctuations. $C_{n}^{2}$ and $C_{T}^{2}$ are in $\left(\mathrm{m}^{-2 / 3}\right)$ and $\left(\mathrm{K}^{2} \mathrm{~m}^{-2 / 3}\right)$, respectively.

Using the Monin-Obukhov Similarity Theory (MOST), the sensible heat flux $P$ । can be obtained from a combination of $C_{T}^{2}$ and additional $\mathrm{w}$ eed data through the following dimensionless relationship

$\frac{C_{T}^{2}\left(z_{\mathrm{LAS}}-d\right)^{2 / 3}}{T_{*}^{2}}=f_{T}\left(\frac{z_{\mathrm{LAS}}-d}{L}\right)=c_{T^{1}}\left(1-c_{T^{2}} \frac{z_{\mathrm{LAS}}-d}{L}\right)^{-2 / 3}$

where $L$ is the Obukhov length ( $\mathrm{m})\left(L=\frac{\rho c_{p} T_{T} u_{*}^{3}}{k g H_{\mathrm{IAS}}}\right)$, the $T^{*}$ is the temperature scale $\left(T_{*}=\frac{-H_{\mathrm{LAS}}}{\rho c_{p} u_{*}}\right)$, and $u^{*}$ the friction velocity expressed as

$u_{*}=k u\left[\operatorname{Ln}\left(\left(z_{\mathrm{LAS}}-d\right) / z_{0}\right)-\psi\left(\left(z_{\mathrm{LAS}}-d\right) / L\right]^{-1}\right.$

where $z_{\text {LAS }}$ is the effective height of the LAS above the surface. Here, $z_{\text {LAS }}$ was estimated following the procedure of Hartogensis (2003), which takes into account the change in topography the LAS transect between the transmitter and the receiver. $\psi$ is the integrated stability function (Panofsky and Dutton, 1984), $d$ is the displacement height, $z_{0}$ is the roughness length, $k$ is the Von Karman constant, $g$ is the gravitational acceleration, $\rho$ is the density of air and $c_{p}$ is the specific heat of air at constant pressure. During the iteration procedure, the Bowen ratio is evaluated using the $H_{\mathrm{LAS}}$, net radiation $\left(R_{n}\right)$, soil heat flux $(G)\left[\beta=\left(H_{\text {LAS }} /\left(R_{n}-G-H_{\text {LAS }}\right)\right)\right]$. In this study we wi $-\rho$ ine ourselv $\epsilon-$ instable conditions and will use the MOS $\equiv$ tionship $f_{T}$ is 2 given by De Bruin et al. (1993).

\section{Available energy}

\section{Net radiation}

The net radiation quantifies the energy available for crop evapotranspiration, photosynthesis, and soil heating (Monteith and Unsworth, 1990). It is the biggest or most important term of the surface energy balance equation. In the current study, the net radiation was expressed as follows:

$R_{n}=(1-\alpha) R_{g}+\varepsilon_{S} R_{a}-R_{t}$ where $\alpha$ is the surface albedo, $R_{g}$ is the solar global radiation [W $\left.\mathrm{m}^{-2}\right], \varepsilon_{S}$ is the surface emissivity which has an almost constant value (in practical work a value of 0.98 , may be taken for crop canopies; Ortega Farías et al., 2000), $R_{a}$ the atmospheric radiation which is emitted by air molecules $\left[\mathrm{W} \mathrm{m}^{-2}\right]$ and $R_{t}$ is the terrestrial radiation which is emitted by the surface $\left[\mathrm{W} \mathrm{m}^{-2}\right]$. By using the Stefan-Boltzman equation (Monteith and Unsworth, 1990), $R_{a}$ an could be expressed as functions of air and surface temperatı respectively. Then Eq. (4) can be rewritten as

$R_{n}=(1-\alpha) R_{g}+\varepsilon_{S} \sigma\left(\varepsilon_{a} T_{a}^{4}-T_{\text {surf }}^{4}\right)$

with $\varepsilon_{a}$ as the emissivity of the atmosphere, $T_{a}$ is the air temperature $[\mathrm{K}], T_{\text {surf }}$ is the surface temperature [K], and $\rho$ is the Stefan-Boltzman constant $\left(5.67 \times 10^{-8} \mathrm{~W} \mathrm{~m}^{-2} \mathrm{~K}^{-4}\right)$.

The $\varepsilon_{a}$ is calculated usin expression proposed (1975) as

$\varepsilon_{a}=1.24\left(e_{a} / T_{a}\right)^{1 / 7}$

with $e_{a}$ as the air vapor pressure (hPa).

\section{Soil heat flux}

The soil heat flux is the conduction of energy per unit area in response to a temperature gradient. It is the most difficult scalar to measure accurately at the appropriate space-scale, due to the complexity of surface cover and physical processes occurring in the soil. Therefore, in several micrometeorological studies $G$ is parameterized as a constant proportion of $R_{n}$ (i.e. $G=c R_{n}$ ) that is fixed for the entire day or period of interest (Mer i et al., 1999; Norman et al., 1995, 2000; Crawford et al., 200 z constant is typically around 0.3 for the sparse canopies and ranges from 0.15 to 0.40 in the literature (Brutsaert, 1982; Choudhury, 1987; Humes et al., 1994; Kustas and Goodrich, 1994). As reported in Santanello and Friedl (2003), $G$ is unfortunately neither constant nor negligible on diurnal time scales. $G / R_{n}$ can range from 0.05 to 0.50 and is driven by several factors: 1 f day, soil moisture and thermal properties, as well as the an 1993). In this study, the ratio of the soil heat flux to net radiation was calculated according to Santanello and Friedl (2003) as follows:

$G / R_{n}=A \cos [2 \pi(t+10800) / B]$

where $t$ is the time of day in seconds, and $A$ and $B$ are adjusting factors which were set by Santanello and Friedl (2003) as 0.31 and 74000 s, respectively. Recently, Hoedjes et al. (2008), Chehbouni et al. (2008) have tested this relationship over a complex field of olive tr ensift Al Haouz basin, Morocco) and a semi-arid mixed agric $\equiv$ land (Yaqui Valley, Mexico), respectively. They found reasonably good results when comparing the measured and estimated values of $\mathrm{AE}$. The RMSE were $51 \mathrm{~W} \mathrm{~m}^{-2}$ (maximum value was about $\left.600 \mathrm{~W} \mathrm{~m}^{-2}\right)$ and $3 \mathrm{~W} \mathrm{~m}^{-2}\left(\mathrm{mi}^{2} \mathrm{n}\right.$ value was about $500 \mathrm{~W} \mathrm{~m}^{-2}$ ), re $\underline{\underline{\underline{\nu}}}$ rely.

Agg $1 \stackrel{\equiv}{\equiv}$ approach

In this section, a simple aggregation scheme was used to estimate the area-average available energy. As reported in Chehbouni et al. (2008), this procedure is based on two assumptions. The first one 1 is of formulating grid-scale surface fluxes using the same $\equiv$ ions that govern patch-scale behavior, but whose arguments are the aggregate expressions of those at the patch-scale. The second one stipulates that "the effective area-average value of a land surface parameter is defined as a weighted average over the component land types in each grid, through that function involving the parameter which most succinctly expresses its relationship with the associated surface flux" (Shuttleworth et al., 1997). Applying this 
simple aggregation rule to area-averaged (denoted by angle brackets) net radiation and soil heat flux leads to:

$\left\langle R_{n}\right\rangle=(1-\langle\alpha\rangle) R_{g}+\left\langle\varepsilon_{S}\right\rangle \sigma\left(\varepsilon_{a} T_{a}^{4}-\left\langle T_{\text {surf }}^{4}\right\rangle\right)$

$\frac{\langle G\rangle}{\left\langle R_{n}\right\rangle}=A \cos [2 \pi(t+10800) / B]$

Similarly, the application of the second assumption leads to the following set of relationships between local (subscript i) and effective (in brackets) radiative temperature, surface emissivity, surface albedo, displacement height, and roughness length (Chehbouni et al., 2008)

$$
\begin{aligned}
& \left\langle T_{\text {surf } /}\left[\frac{\sum_{1}^{3} f_{i} \varepsilon_{i}\left(T_{\text {surf }}\right)^{4}}{\langle\varepsilon\rangle}\right]^{0.25}\right. \\
& \langle\varepsilon\rangle=\sum_{1}^{3} f_{i} \varepsilon_{i} \\
& \langle\alpha\rangle=\sum_{1}^{3} f_{i} \alpha_{i} \\
& \langle d\rangle=\sum_{1}^{3} f_{i} d_{i} \\
& \ln \left\langle z_{0}\right\rangle=\sum_{1}^{3} f_{i} \ln \left(z_{0_{i}}\right)
\end{aligned}
$$

where $f_{i}$ is the fraction of the surface covered by the patch $i$ with, obviously, $\sum_{i} f_{i}=1$.

The area-average estimates of available energy $\langle\mathrm{AE}\rangle\left(=\left\langle R_{n}\right\rangle\right.$ $-\langle G\rangle)$ were combined with the estimates of sensible hea rom the LAS to obtain the area-average latent heat flux, $\left\langle\mathrm{LE}_{\mathrm{I} A \mathrm{C}} \equiv\right.$ :sidual in the surface energy balance equation, i.e.

$\left\langle\mathrm{LE}_{\mathrm{LAS}}\right\rangle=\langle\mathrm{AE}\rangle-\left\langle H_{\mathrm{LAS}}\right\rangle$

\section{Experimental site and measurements}

The study took place in Wankama catchment, between Day of Year (DOY) 204 and 225 (July 23rd-August 13th) in 2006. This catchment is located near the cit iamey, Niger. In this section, site description and experimen the reader is referred to Cappelaere et al.(thic issue) for a complete description. The climate is typically Sal with a short rainy season from June to September and high 2 satures throughout the year. Potential evapotranspiration is about $2500 \mathrm{~mm}$ per year. The catchment is intensively cultivated: $54 \%$ planted fields (mainly millet), and 26\% of the field lands fallow (Peugeot et al., 2003); the remaining area is classified as degraded shrubs.

The LAS used in this study was developed and built by the Meteorology and Air Quality Group (Wageningen University, the Netherlands). This instrument has been constructed according to the basic design described in Ochs and Wilson (1993). It has an aperture size of $0.15 \mathrm{~m}$ and the transmitter operates at a wavelength of $0.94 \mu \mathrm{m}$. At the receiver, $C_{n}^{2}$ is sampled at $1 \mathrm{~Hz}$ and averaged over 1-min intervals by a CR510 data logger (Meijninger et al., 2000). Th smitter and the receiver were mounted on $10-\mathrm{m}$ high towt th an altitude difference of approximately The receiver was installed at the highest part of the basin (pli
while the transmitter was installed at the lowest part of the basin (Fig. 1). The LAS was set up over a $3.2 \mathrm{~km}$ transect spanning three vegetation types-fields of millet, fallow fields, and areas of degraded shrub. The direction of the LAS path was $250^{\circ}$ from North. Analysis of the wind direction pattern during the study period showed that the dominant (70\%) wind direction is situated within an interval ranging from $157.5^{\circ}$ to $247.5^{\circ}$ (see Fig. 2).

Along the LAS transer three vegetation types have been instrumented with eddy, let (denoted "site A") and fallow (denoted "site B")-were instrumented since 2005 (Ramier et al., this issue). In order to measure representative fluxes along the transect of the LAS, in 2006 we installed a third EC system over the degraded shrubs site (denoted "site C"): see Fig. 1. The EC systems, installed at the A and B sites, consisted of a 3D sonic anemometer (CSAT3, Campbell Scientific Ltd.) and an open-path infrared gas analvser (Li7500, Licor Inc.). At the third site-i.e. "site C"-the EC s consisted of a 3D sonic anemometer (CSAT3, Campbell Scir hygrometer $\left(\mathrm{KH}_{2} \mathrm{O}\right.$, Campbell Scientific Ltd.). Raw data were sampled at a rate of $20 \mathrm{~Hz}$ and were recorded using CR5000 data loggers (Campbell Scientific Ltd.). The half-hourly fluxes were later calculated off-line using two post-processing software package: ECpack and EdiRe, which are developed, respectively, by the Meteorology and Air Quality Group at Wageningen University and by

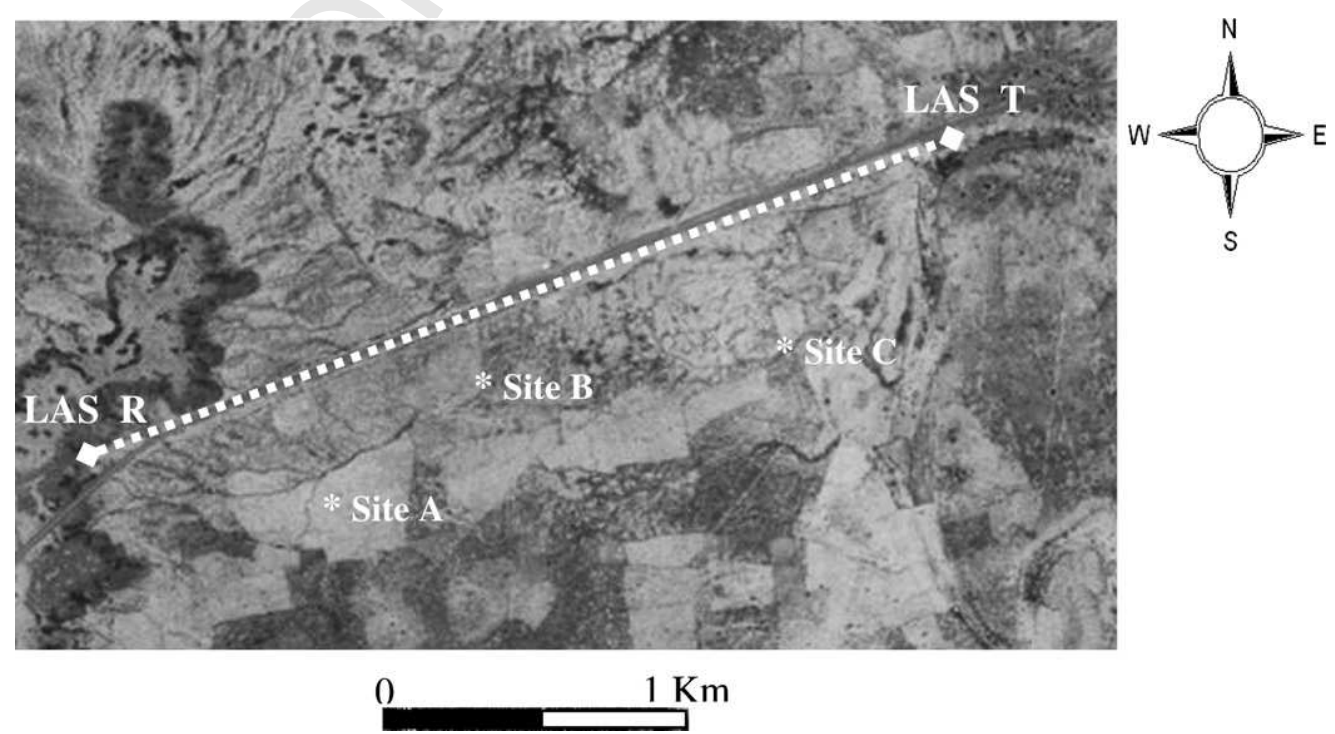

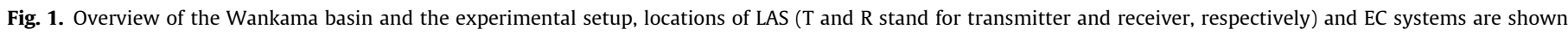
(Sites A, B, and C). 


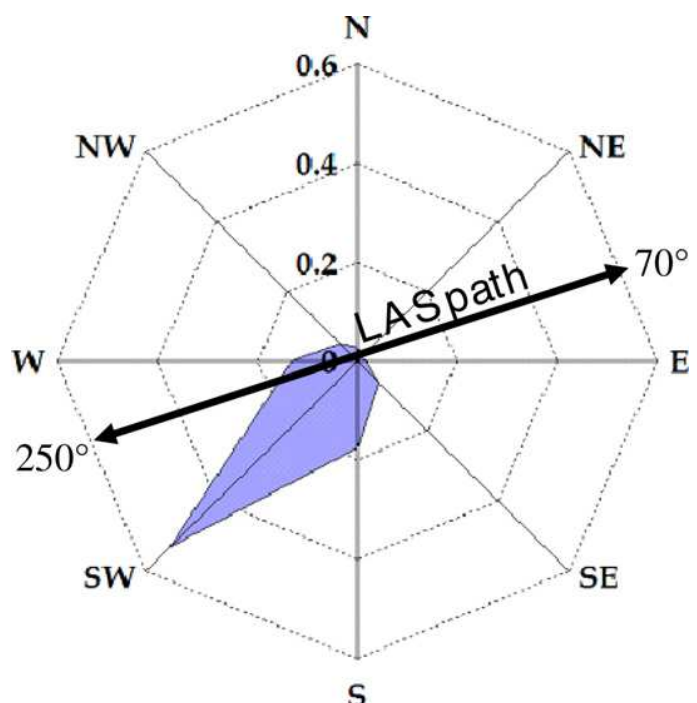

S

Fig. 2. Mean frequency of wind direction during the study period (DOYs 204-225)

Edinburgh University. The ECpack and EdiRe are available for download from http://www.met.wau.nl/ and http://www.geos.ed.ac.uk/abs/research/micromet/EdiRe/Downloads.html, respectively. For the ECpack software, the fluxes were calculated after performing planar fit corrections (Wilczak et al., 2001), correcting the sonic temperature for the presence of humidity (Schotanus et al., 1983), frequency response corrections for slow apparatus and path length integration (Moore, 1986), the inclusion of the mean vertical velocity according to Webb et al. (1980), and oxygen correction for the Krypton hygrometer, which is sensitive to $\mathrm{O}_{\text {, }}$ (Van Dijk et al., 2003). For the EdiRe software, the fluxes were c culated after despiking, double rotation, Webb correction and 1 cross-correlation for derivation of time lag between the sonic anemometer and the gas analyser (Cappelaere et al., this issue). It is certainly unfortunate that tw been used. This is due to the e EC were $\mathrm{n}$ : $\mathrm{d}$ by two groups and we did not have access to raw data for "site A" and "site B". Nevertheless, we did perform a comparison of the two postprocessing programs using one week of data over "site C". The correspondence in terms of sensible heat flux estimates was very good $\left(R^{2}=0.99\right.$ and $\left.\mathrm{RMSD}=6.7 \mathrm{~W} \mathrm{~m}^{-2}\right)$. It can be thus concluded that ifference between th -1 programs is not very significant, st under the preva: study.

In the vicinity of each EC tower, a set of standard meteorological instruments were installed to measure net radiation using the Q7 net radiometer (REBS Inc., WA, USA) over "site C" and the CNR1 (Kipp and Zonen, the Netherlands) over "site A" and "site B", air temperature and humidity using a Vaisala (HMP45AC temperature and humidity probe), soil heat flux at different depths using the soil heat flux plates (HFT3-L, Campbell Scientific Ltd.), and surface temperature using the Precision Infrared temperature sensor (IRTS-P) over "site C". Over "site A" and "site B," the surface temperature was inverted from the CNR1 measurements. In addition, two CM3 pyranometers were installed over "site C" to measure incoming and outgoing shortwave (CM3, Campbell Scientific Ltd.).

\section{Results and discussion}

In this section, we first compare the LAS-based estimates of area-average sensible heat flux values to those constructed as area-average from measured values of sensible heat flux using the three EC systems (from here on, the constructed fluxes will be called measured). Second, the estimated and measured areaaverage AE were compared. Thereafter, we evaluate the applicability of the LAS to estimate the evapotranspiration flux over the Wankama catchment through the comparison of measured and estimated values. In this study, we will only consider daytime observations with half-hourly time scale, from 07:30 UTC until 18:00 UTC, since the behavior of the temperature structure parameter is not well known for stable conditions which can create greater uncertainty in the fluxes, especially over heterogeneous surfaces.

It should be noted that during this study, about $9 \%$ of LAS data was lost due to rainfall and very strong wind associated with storms which disturbed the alignment of the LAS. However, knowing that this study was undertaken during the rainy season, this quantity can be considered as being very small: during the rainy season, most rain falls during the night, which minimizes the loss of daytime data.

\section{Sensible heat flux estimated by LAS}

In this study, the EC data were used for assessing the accuracy of the LAS. Therefore, an analysis of the energy balance flux components was performed first. The comparison between the available energy $\left(R_{n}-G\right)$ and the sum of the latent and sensible heat fluxes $\left(\mathrm{H}_{\mathrm{Fr}}+\mathrm{I}-i\right.$ isured independently by the EC systems, showed d $\underline{E}$ E ion of the fluxes $\left(H_{\mathrm{F} r}+\mathrm{LE}_{\mathrm{EC}}\right)$ by about $8 \%, 17 \%$, $\mathrm{J} \%$ for the A, B. and C sites, $\mathrm{rt}$ ively. The problem of the energy balance no ure canno ntirely explained by the mismatch of the : representative for the convective fluxes and available energy measurements nor by uncertainties associated with measurement of soil heat flux and net radiation (Twine et al., 2000; Hoedjes et al., 2002, 2008; Chehbouni et al., in press). In this study, we chose to follow the approach suggested ine et al. (2000), which consists of considering that, althou system underestimates sensible and latent heat fluxes, their ratio (the Bowen ratio) is correctly measured. Based on this assumption, we recalculated sensible and latent heat fluxes-over each, individual site-using measured Bowen ratio and available energy, thus forcing the closure of the energy balance. This correction is important in the case of comparison with the LAS, since LAS calculations of $H$ and LE are made using an iterative procedure involving $R_{n}$ and $G$, and thus based on the principle of conservation of energy ( jes et al., 2002).

Before evaluating the accuracy of the LAS, a footprint analysis was made. In this study, we used the analytical footprint model proposed by Horst and Weil $(1992,1994)$. The theoretical background of this model is briefly given in Appendix A. Fig. 3a and b shows the footprints of the LAS and EC (corresponding to approx. ly $95 \%$ of the sensible heat flux) for two wind intervals, $70^{\circ}$ to and $250^{\circ}$ to $70^{\circ}$, respectively. It can be seen that wht wind con $\mathrm{m}$ the interval $70^{\circ}$ to $250^{\circ}$, the footprint , LAS cover area where the tems are installed (Fig. 3a), thus the LAS fluxes are more or sured by the EC systems. On the contrary, when the wind comes from the $250^{\circ}$ to $70^{\circ}$ interval, the footprint of the LAS (which spans more de 1 fields) and the EC systems differed strongly (Fig. 3b), $\equiv$ ng large differences between LAS fluxes and those measured by the EC. Consequently, we will only consider the fluxes associated with wind from the $70^{\circ}$ to $250^{\circ}$ wind interval.

Fig. 4 displays a compariss -2 ween area-average sensible heat fluxes derived from the $\left.\left.\mathrm{L} \equiv I_{\mathrm{IAS}}\right\rangle\right)$ and those obtained by weighting the values measured at ing the EC systems

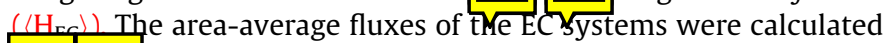
Pat the local values obtained by each EC system are repfor the sites where those systems are installed along the basin. Sites A, B, and C represented about $54 \%, 26 \%$, and $20 \%$ 

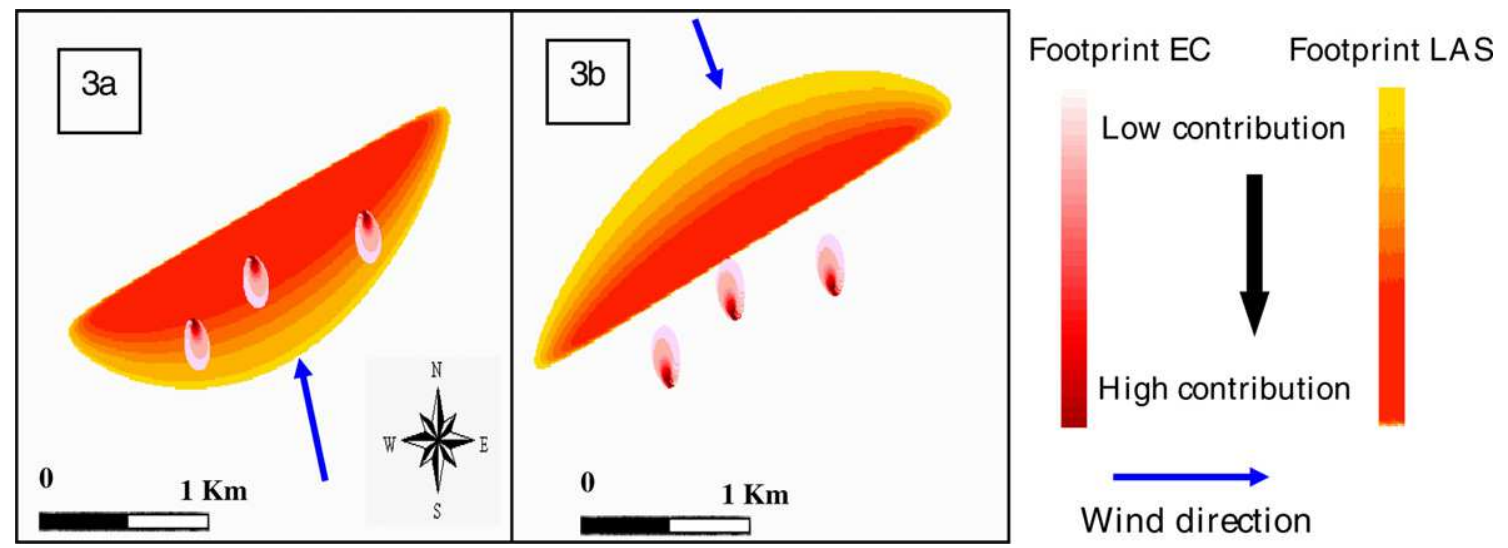

Fig. 3. Footprint of the LAS and EC systems, calculated using the footprint model of Horst and Weil (1994) for the wind coming from the intervals $70^{\circ}$ to $250^{\circ}$ (a) and $250^{\circ}$ to $70^{\circ}(\mathrm{b})$.

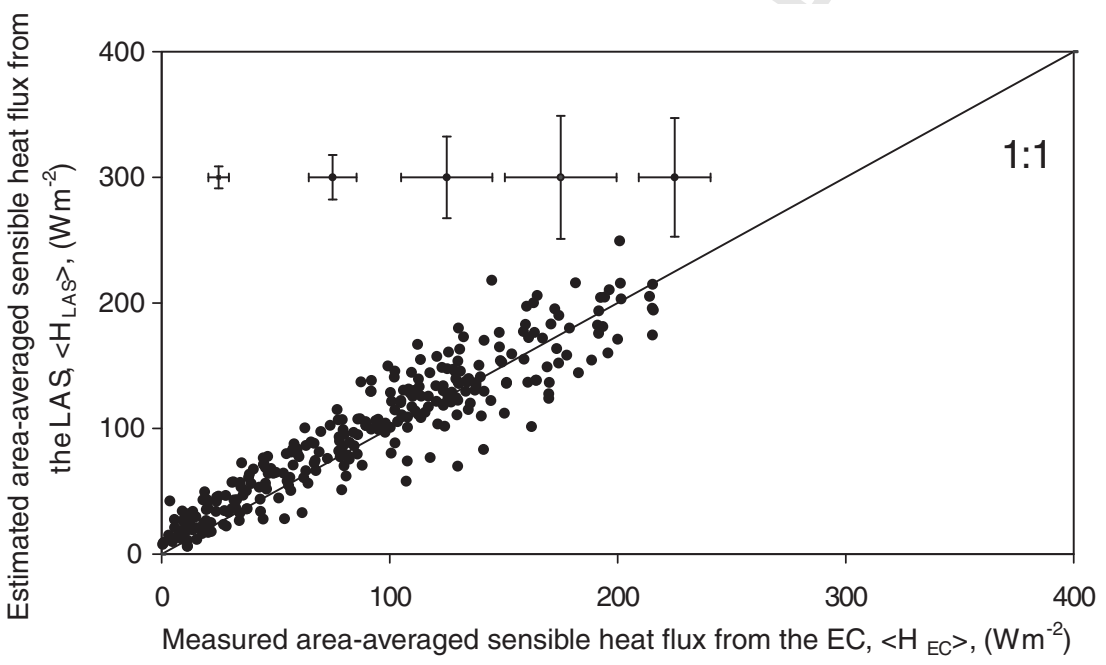

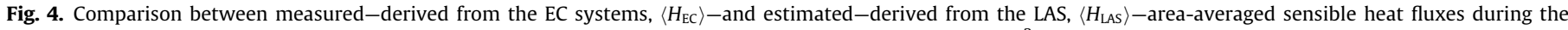
study period (DOYs 204-225). The error bars represent the average uncertainly of the fluxes for each $50 \mathrm{~W} \mathrm{~m}^{-2}$ interval.

Table 1

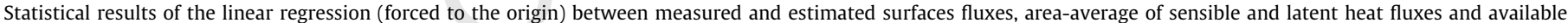

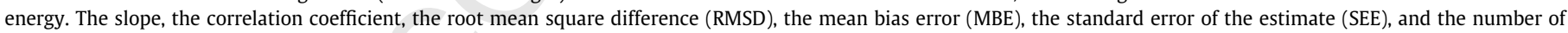
samples are presented.

\begin{tabular}{|c|c|c|c|c|c|c|}
\hline & Slope & $R^{2}$ & RMSD & MBE & SEE & $n$ \\
\hline Sensible Heat flux, $H$ & 1.03 & 0.85 & 21.59 & 7.38 & 21 & 291 \\
\hline Available energy, AE & 0.93 & 0.83 & 59.53 & -24 & 55.44 & 370 \\
\hline Latent heat flux, LE (using the estimated $\mathrm{AE}$ ) & 0.83 & 0.72 & 64 & -36.5 & 50 & 254 \\
\hline
\end{tabular}

of the Wankama catchment. The statistical results-including the slope, correlation coefficient $\left(R^{2}\right)$, the root mean square difference (RMSD), standard error of th $\rho$ lates (SEE), and mean bias error (MBE)-are shown in Table $1 \equiv \mathrm{n}$ be seen that the LAS sensible heat fluxes agree quite well with those derived from the EC systems. The $\left\langle H_{\mathrm{I} \text { AS }}\right\rangle$ is $3 \%$ higher than $\left\langle\mathrm{H}_{\mathrm{FC}}\right\rangle$ with a relative error of about 20\%

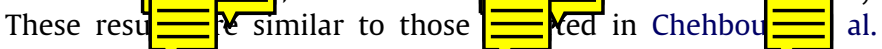
(1999, $200 \equiv$ i press) and Meijni: $\equiv$ tal. (2006) ove: $\equiv$ geneous surfac -2 hough the correspondence between $\left\langle H_{\text {LAS }}\right\rangle$ and $\left\langle H_{\mathrm{EC}}\right\rangle$ is gor $\equiv$ ne scatter is still seen. This can be explained by several factors: the contrast in the footprint scale (see Fig. 3a) with is amplified by the strong heterogeneity along the LAS path due to the changes in vegetation type and cover, as well as to topography; and the uncertainties of the similarity stability functions.

To illustrate this heterogeneity, the daytime evaporation rates measured over each site, which is defined as the ratio of the latent heat flux and the sum of the sensible and latent heat fluxes, were plotted in Fig. 5. Here, it can be seen that the curves of the evaporation rate for "site $A$ " and "site C" are close, with a difference of only about $4 \%$. For "site B," the evaporation rate was very high 


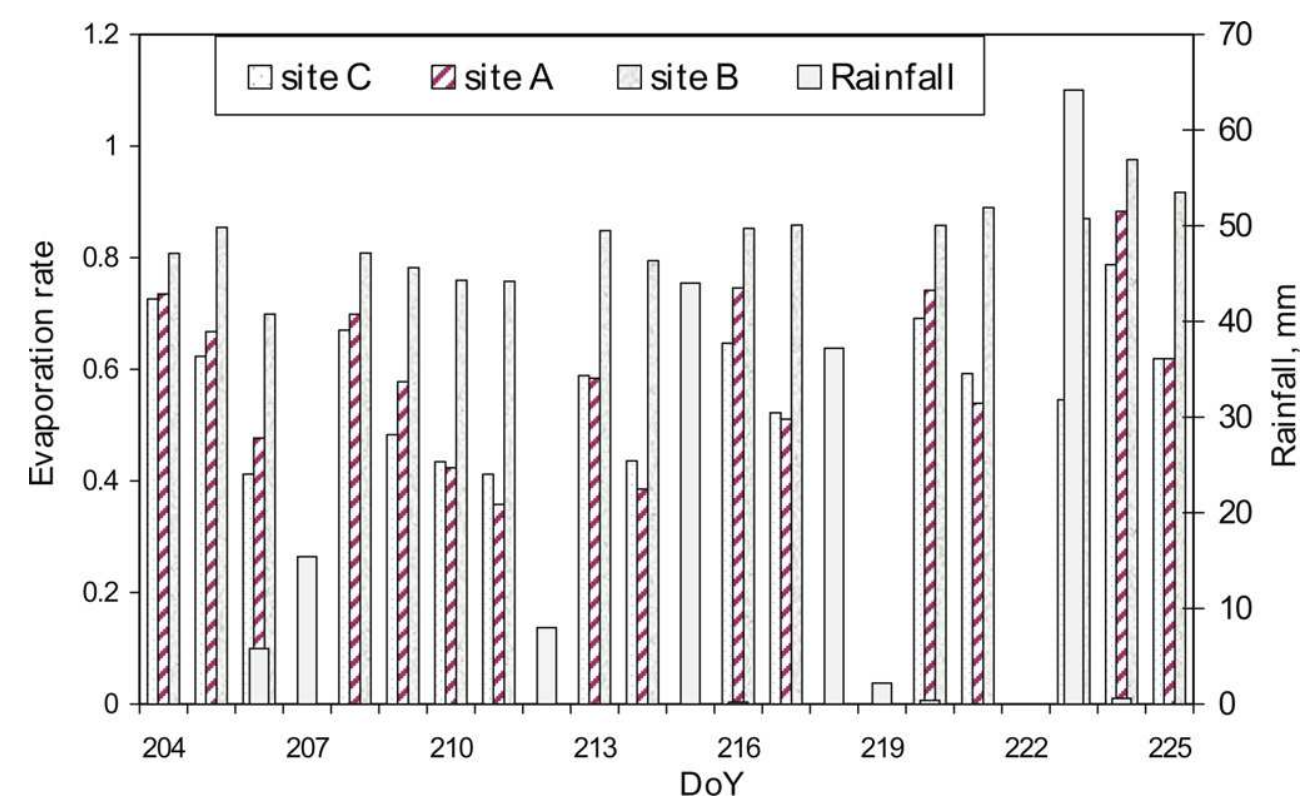

Fig. 5. Daily evaporation rate estimated at the three EC sites during the study period (DOYs 204-225). The rainfall is shown in the same figure.

compared with that of the other sites. This was expected, however, owing to the type of vegetation encountered at "site B"(savannah with a height of $3 \mathrm{~m}$ ).

\section{Estimating available energy}

In many practical applications, area-average observations of net radiation and soil heat flux are not available, especially at the scintillometer footprint scale. However, providing a spatial distribution of surface temperature, albedo, and solar radiation from the satellite images (i.e. MODIS, ASTER), one can estimate the available energy at the catchment scale, using the proposed aggregation approach Eqs. (8)-(12). In the current study, the local measurements of the surface temperature, the albedo, and the incoming solar radiation have been used to estimate the area-averaged available energy $\left(\left\langle\mathrm{AE}_{\text {ost }}\right\rangle\right)$, assuming that these local measurements are representative of the individual site. The albedo and the incoming solar radiation were calculated as area-weighted averages of those measured over the three sites. The effective surface temperature was obtained by combining Eqs. (10) and (11). In order to quantify the error related to the appli - of - ggregation rules to the flux estimation, the estin $\angle \mathrm{AE} \equiv$ against the measured values $-\left\langle\mathrm{AE}_{\text {meas }}\right\rangle$, obtain veighted averages of those mea over the three sit, ear regression shows $\left.1 \equiv \mathrm{E}_{\text {est }}\right\rangle$ is $7 \%$ lower than $\left\langle\mathrm{AE}_{\text {meas }}\right\rangle$, with a relative error of about $34 \%\left(R^{2}=0.83, \mathrm{RMSD}=59.53 \mathrm{~W} \mathrm{~m}^{-2}\right.$ and $\mathrm{SEE}=55.44 \mathrm{~W} \mathrm{~m}^{-2}$ : Table 1$)$. $\rho^{-\rho}$ :sult indicates that $\mathrm{t}-$;regation schemt not exact al $\bar{\equiv}$ ors are associated $\mathrm{n} \equiv$ me of the assump $\equiv$ ised to derive them. Additionally, it is important to mention that the use of the Brutsaert's formula for estimating the atmospheric radiation-which was established for clear sky conditions only-may create an extra scatter between measured

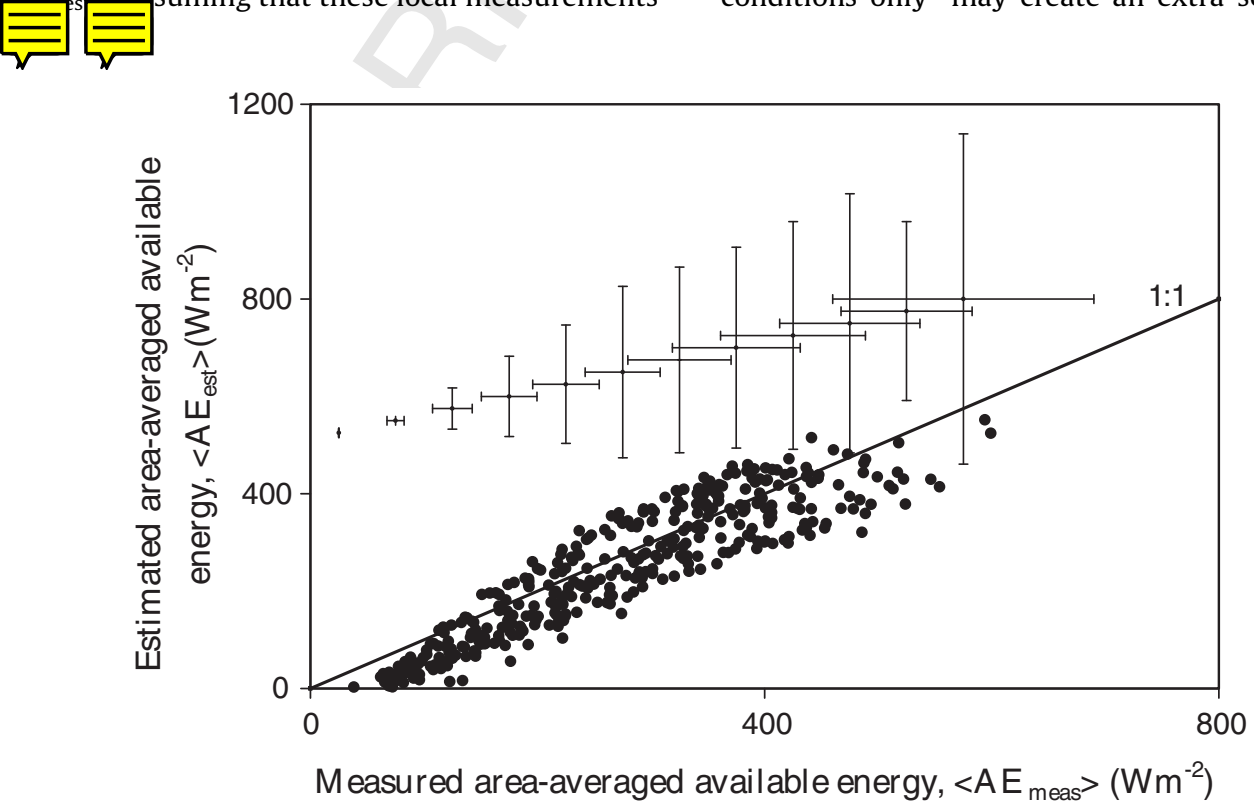

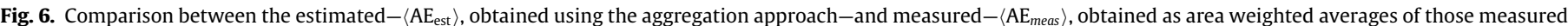

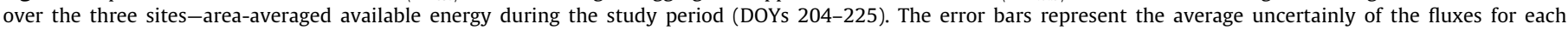
$50 \mathrm{~W} \mathrm{~m}^{-2}$ interval. 


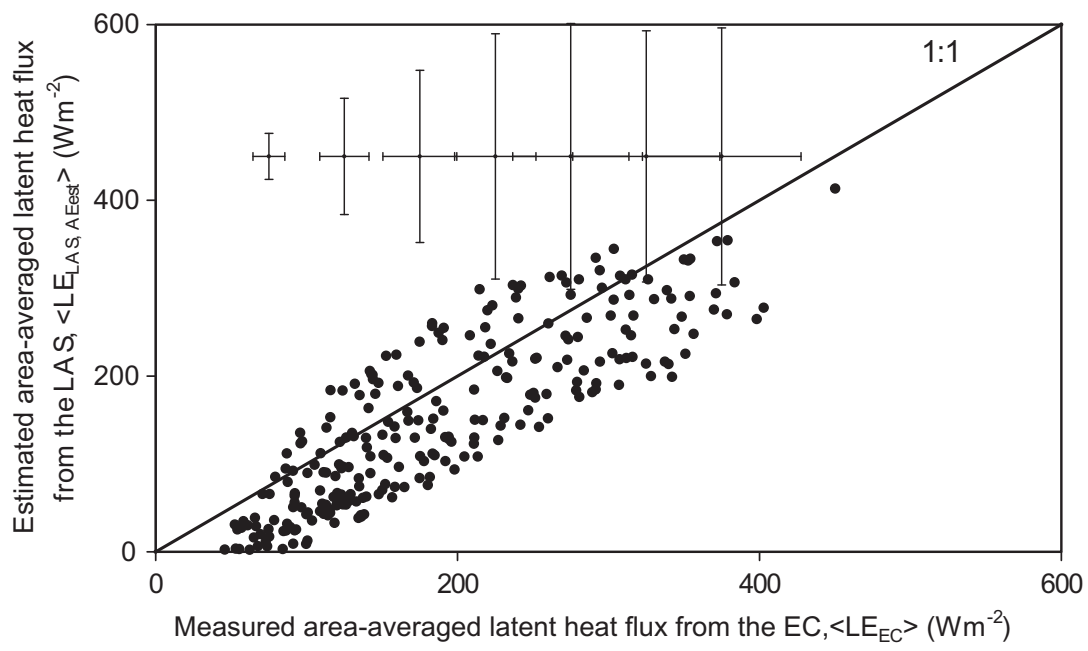

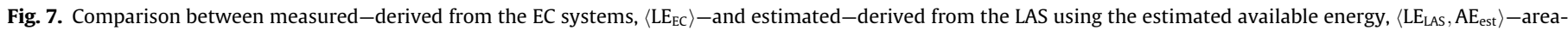
averaged latent heat fluxes during the study period (DOYs 204-225). The error bars represent the average uncertainly of the fluxes for each $50 \mathrm{~W} \mathrm{~m}^{-2}$ interval.

and estimated net radiation (Ezzahar et al., 2007a). Therefore, this scatter can be translated to the soil heat flux, since the latter was estimated as a fraction of net radiation. Overall, these results showed that, at least under the prevailing conditions of this study, the proposed approach leads to accurate estimates of instantaneous area-averaged available energy over heterogeneous and contrasted surfaces.

\section{Latent heat flux}

The estimated area-average latent heat flux from the LAS (denoted $\left.\left\langle L_{I A S}, A E_{\text {oct }}\right\rangle\right)$ was obtained as the residual term of the energy balan $\quad\left\langle\mathrm{AE}_{\text {oct }}\right\rangle$ (Eas. (1)-(15)). Fig. 7 displays a

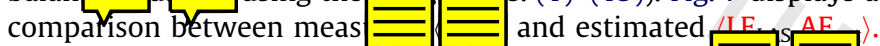
Measured $\left\langle\mathrm{LE}_{\mathrm{EC}}\right\rangle$ was obtair $\equiv$ averaging later measured over the three sites using EC systems. The 1 sion shows that $\left\langle\mathrm{LE}_{\mathrm{IAS}}, \mathrm{AE}_{\mathrm{\rho ct}}\right\rangle$ is $17 \%$ lower than $\left\langle\mathrm{LE}_{\mathrm{EC}}\right\rangle$, with a relative error of abou $=0.72, \quad \mathrm{RMSD}=64 \mathrm{~W} \mathrm{~m}^{-2}$ and $\mathrm{SEE}=$ $50 \mathrm{~W} \mathrm{~m}^{-2}$ : Tab

\section{are several es} be $\equiv$ measured and estimated area-average latent heat fluxes. First, the effect of the contrast in the footprint scale: the LAS covers approximately the entire basin and the EC fluxes were local measurements; the area averages of EC were calculated by assuming that the measurements were representative for each of the sites from which they were taken. Second, the errors associated with the estimated available energy, which can have a big impact on the estimation of $\left\langle\mathrm{LE}_{\mathrm{IAS}}, \mathrm{AE}_{\mathrm{est}}\right\rangle$, since the sensible heat fluxes from the LAS agree we 1 th the results show $\equiv$ at, and environmental conditions within the considered study, the combination of the LAS and an aggregation scheme leads to reasonably accurate estimates of area-average latent heat flux over heterogeneous, contrasted, and non-uniform surfaces.

\section{Conclusions and perspectives}

Within the AMMA program, we have investigated the performance of an approach combining the Large Aperture Scintillometer (LAS) measurements and an aggregation scheme to estimate the latent heat flux over the entire basin of Wankama. The LAS was installed over a $3.2 \mathrm{~km}$ slanted, heterogeneous, and contrasted path with a difference in altitude between the receiver and the transmitter of approximately $46 \mathrm{~m}$. Micrometeorological instruments were deployed over several sites along the LAS path. These included classical meteorological stations, turbulent fluxes using eddy covariance devices, net radiation and soil heat flux measuring devices. We found that the sensible heat flux derived from the LAS agrees reasonably well with area-average EC fluxes, with a relative error of approximately $20 \%\left(R^{2}=0.85, \mathrm{RMSD}=21.56 \mathrm{~W} \mathrm{~m}^{-2}\right.$ and $\mathrm{SEE}=21.39 \mathrm{~W} \mathrm{~m}^{-2}$ ), despite $1=$ ntrast in footprint $\mathrm{s}$ wich is amplified $\rho$ e heteroger by the unce es of the similarity stability functions over heterogeneous surfaces. This result is of great interest because it indicates that the LAS can be effectively used to accurately estimate spatially-averaged sensible heat flux over complex terrains.

Additionally, the area-average latent heat flux was derived as the residual term of the energy balance equation through the combination of an aggregation scheme to derive area-average available energy and the LAS measurements. The comparison of the estimated latent heat flux (obtained using the aggregated available energy) against the area-average EC measurements yielded an acceptable agreement with an underestimation of $17 \%$ and a relative error of $34 \% \quad\left(R^{2}=0.72\right.$ and $\mathrm{RMSD}=64 \mathrm{~W} \mathrm{~m}^{-2}$, $\mathrm{SEE}=50 \mathrm{~W} \mathrm{~m}^{-2}$ ). This diff $\quad$ : was related basically to the error in the es on of the ar energy, especially for low values (less tha $\mathrm{W} \mathrm{m}^{-2}$ ), since the comparison of the sensible heat fluxes betweer $A$ AS and the EC yielded a good agreement. In spite of this sc, $\mathrm{t}$ can be concluded that these results demonstrate the potential of the proposed model (a combination of the LAS together with the aggregation scheme) to estimate latent heat flux over large and heterogeneous areas.

The proposed model to aggregate the available energy used local measurements of surface temperature, albedo, and solar radiation, and assumed that these local measurements are representative of the individual sites. This assumption can certainly lead to some errors because the heterogeneity is also encountered at the field or patch scale. To overcome this problem, a forthcoming investigation will address the possibility of using MODIS data to derive spatially-distributed available energy before aggregating it according to the LAS footprint, in order to assure spatial matching of the $H$ and AE scales.

Finally, despite the limitations mentioned above, one can safely conclude that the proposed approach is reasonably adequate for routinely quantifying the values of LE at a catchment scale. The 
implication of this result is of great importance for improving the parameterization of land surface fluxes in meso-scale models. This result is also of great interest for hydrological modeling and, therefore, for water resources management. Indeed, accurate basin scale estimates of LE will significantly help in assessing the overall performance of hydrological models. In this regard, Chaponnière et al. (2007) have shown that the fact that a hydrological model correctly simulates the observed runoff does not mean that intermediate processes such as the interaction between ground water and surface water or basin evapotranspiration are well reproduced.

\section{Acknowledgements}

This study has been funded by the Institut de Recherche pour le Développement (IRD). Additional funding was provided by the E.U. through the AMMA and PLEIADES projects. AMMA was developed by an international scientific group and is currently funded by a large number of agencies, especially from France, the UK, the US, and Africa. It has been the beneficiary of a major financial contribution from the European Community's Sixth Framework Research Program. Detailed information on scientific coordination and funding is available on the AMMA International website http:// www.ammainternational.org.

\section{Appendix A}

The contributing surface-to-scalar flux measurement from the LAS, called the source area (SA), was calculated using the analytical footprint model proposed by Horst and Weil $(1992,1994)$. The footprint function $f$. or the contribution per unit surface flux of each unit element upwind surface area to a measured vertical flux, relates to $\mathrm{t}$ tical flux measured at height $z_{m}, F\left(x, v \cdot z_{m}\right)$. to the spatial distribution of surface fluxes, $F(x, v, z=0) \quad, y$ (Horst and Weil, 1994) i.e.

$F\left(x, y, z_{m}\right)=\int_{-\infty}^{\infty} \int_{\infty}^{x} F_{0}\left(x^{\prime}, y^{\prime}\right) f\left(x-x^{\prime}, y-y^{\prime}, z_{m}\right) a x a y^{\prime}$

where $x$ and $y$, respectively, are the upwind and crosswind dis; (m) frc - : point where the measurements are taken. )urce are $\quad$; from the integration of the footprint function. In this study, we calculated the crosswind-integrated footprint function using the model of Horst and Weil (1994):

$\overline{f^{y}}\left(x, z_{m}\right) \cong \frac{d \bar{z}}{d x} \frac{z_{m}}{\bar{z}^{2}} \frac{\bar{u}\left(z_{m}\right)}{\bar{u}(c \bar{z})} A \exp \left[-\left(\frac{z_{m}}{b \bar{z}}\right)^{r}\right]$

where $z$ is the mean plume height for diffusion from a surface $\geq$ and $u(z)$ the mean wind speed profile. The variables $A, b$ are ga - unctions of shape parameter $r$. We have assumed that the vio of the MOST is small (Meijninger et al., 2002b). In the case of the LAS, one has to combine $f$ with the spatial weighting function $W(x)$ of the LAS in order to calculate the source area.

\section{Referen}

Allen, R.G., Tasumi, M., Trezza, R., 2007. Satellite-based energy balance for mapping evapotranspiration with internalized calibration (METRIC)-model. Journal of Irrigation and Drainage Engineering 133 (4), 380-394.

Arain, A.M., Michaud, J.D., Shuttleworth, W.J., Dolman, A.J., 1996. Testing of vegetation parameter aggregation rules applicable to the BiosphereAtmosphere Transfer Scheme (BATS) at the Fife site. Journal of Hydrology $177,1-22$.

Bastiaanseen, W.G.M., Menenti, M., Feddes, R.A., Holtslag, A.A., 1998. E remote sensing surface energy balance algorithm for land (SEBAL): I. Formulation. Journal of Hydrology 212-213 (1-4), 198-212.

Brutsaert, W., 1975. On a derivable formula for long-wave radiation from clear skies. Water Resources Research 11, 742-744.

Brutsaert, W., 1982. Evaporation into the Atmosphere. Reidel, Dordrecht.

Caparrini, F., Castelli, F., Entekhabi, D., 2003. Mapping of land-atmosphere heat fluxes and surfaces parameters with remote sensing data. Boundary-Layer Meteorology 92, 73-95.
Caparrini, F., Castelli, F., Entekhabi, D., 2004. Varaiational estimation of soil and vegetation turbulent transfer and heat flux parameters from sequences of multisensor imagery. Water Resources Research 40, W12515. doi:10.1029/ 2004 WR00335.

Cappelaere, B., Descroix, L., et al., (this issue). The AMMA-Catch observing system in the cultivated Sahelian area of south-west Niger - strategy, implementation and site description. Journal of Hydrology (AMMA-Catch Special Issue).

Chaponnière, A., Boulet, G., Chehbouni, A., Arsmouk, L., 2007. Assessing hydrological processes under scarce data and complex environment. Journal of Hydrological Processes. doi:10.1002/hyp.6775.

Chehbouni, A., Njoku, E.G., Lhomme, J.P., Kerr, Y.H., 1995. An approach for averaging surface temperature and surface fluxes over heterogeneous surfaces. Journal of Climate 5, 1386-1393.

Chehbouni, A., Kerr, Y.H., Watts, C., Hartogensis, O., Goodrich, D.C., Scott, R., Schieldge, J., Lee, K., Shuttleworth, W.J., Dedieu, G., De Bruin, H.A.R., 1999. Estimation of area-average sensible heat flux using a large aperture scintillometer. Water Resources Research 35 (8), 2505-2512.

Chehbouni, A., Watts, C., Lagouarde, J.P., Kerr, Y.H., Rodríguez, J.C., Bonnefond, J.M., Santiago, F., Dedieu, G., Goodrich, D.C., Unkrich, C., 2000a. Estimation of heat fluxes and momentum fluxes over complex terrain using a large aperture scintillometer. Agriculture and Forest Meteorology 105, 215-226.

Chehbouni, A., Watts, C., Kerr, Y.H., Dedieu, G., Rodríguez, J.C., Santiago, F., Cayrol, P., Boulet, G., Goodrich, D.C., 2000b. Methods to aggregate turbulent fluxes over heterogeneous surfaces: application to SALSA data set in Mexico. Agriculture and Forest Meteorology 105, 133-144.

Chehbouni, A., Hoedjes, J., Rodríguez, J.C., Watts, C., Garatuza-Payán, J., Kerr, Y.H., 2008a. Remote sensing based estimates of daytime area averaged surface fluxes over contrasted agricultural patchwork in a semi-arid region. Agriculture and Forest Meteorology. doi:10.1111/j.1365-2486.2007.01466.

Chehbouni, A., Ezzahar, J., Watts, C., Rodríguez, J.C., Garatuza Payán, J., in press. Estimating area-averaged surface fluxes over contrasted agricultural patchwork in a semi-arid region. In: Joachim Hill, Achim Röder (Eds.), Advances in Remote Sensing and Geoinformation Processing for Land Degradation Assessment. Taylor and Francis.

Choudhury, B.J., 1987. Relationships between vegetation indices, radiation absorption, and net photosynthesis evaluated by a sensitivity analysis. Remote Sensing of Environment 22, 209-233.

Cleugh, H.A., Leuning, R., Mu, Q., Running, S.W., 2007. Regional evaporation estimates from flux tower and MODIS satellite data. Remote Sensing of Environment 106, 285-304.

Crawford, T.M., Stensrud, D.J., Carlson, T.N., Capehart, W.J., 2000. Using a soil hydrology model to obtain regionally averaged soil moisture values. Journal of Hydrometeorology 1, 353-363.

Crow, W.T., Kustas, W.P., 2005. Utility of assimilating surface radiometric temperature observations for evaporation fraction and heat transfer coefficient retrieval. Boundary-Layer Meteorology 115, 105-130.

De Bruin, H.A.R., Kohsiek, W., Van den Hurk, B.J.J.M., 1993. A verification of some methods to determine the fluxes of momentum, sensible heat and water vapour using standard deviation and structure parameter of scalar meteorological quantities. Boundary-Layer Meteorology 76, 25-40.

Ezzahar, J., Chehbouni, A., Hoedjes, J.C.B., Er-raki, S., Chehbouni, Ah., Bonnefond, J.M., De Bruin, H.A.R., 2007a. The use of the scintillation technique for estimating and monitoring water consumption of olive orchards in a semi arid region. Agriculture Water Management 89, 173-184.

Ezzahar, J., Chehbouni, A., Hoedjes, J.C.B., Chehbouni, Ah., 2007b. On the application of scintillometry over heterogeneous surfaces. Journal of Hydrology 34, 493501.

French, A.N., Jacob, F., Anderson, M.C., Kustas, W.P., Timmermans, W., Gieske, A., Su, Z., Su, H., McCabe, M.F., Li, F., Prueger, J., Brunsell, N., 2005. Surface energy fluxes with the advance spaceborne thermal emission and reflection radiometer (ASTER) at the Iowa 2002 SMACEX site (USA). Remote Sensing of Environment 99, 55-65.

Goutorbe, J.P., Lebel, T., Tinga, A., Bessemoulin, P., Brouwer, J., Dolman, A.J., Engman, E.T., Gash, J.H.C., Hoepffner, M., Kabat, P., Kerr, Y.H., Monteny, B., Prince, S., Said, F., Sellers, P., Wallace, J.S., 1994. HAPEX-Sahel: a large scale study of landatmosphere interactions in the semi-arid tropics. Annales Geophysicae 12, 5364.

Hartogensis, O.K., Watts, C.J., Rodríguez, J.C., De Bruin, H.A.R., 2003. Derivation of an effective height for scintillometers: La Poza experiment in Northwest-Mexico. Journal of Hydrometeorology 4 (5), 915-928.

Hemakumara, H.M., Chandrapala, L., Moene, A.F., 2003. Evapotranspiration fluxes over mixed vegetation areas measured from large aperture scintillometer. Agriculture Water Management 58, 109-122.

Hoedjes, J.C.B., Zuurbier, R.M., Watts, C.J., 2002. Large aperture scintillometer used over a homogeneous irrigated area, partly affected by regional advection. Boundary-Layer Meteorology 105, 99-117.

Hoedjes, J.C.B., Chehbouni, A., Jacob, F., Ezzahar, J., Boulet, G., 2008. Deriving daily evapotranspiration from remotely sensed instantaneous evaporative fraction over olive orchard in semi-arid Morocco. Journal of Hydrology 354, 53-64.

Horst, T.W., Weil, J.C., 1992. Footprint estimation for scalar flux measurements in the atmospheric surface layer. Boundary-Layer Meteorology 59, 279-296.

Horst, T.W., Weil, J.C., 1994. How far is far enough? The fetch requirements for micrometeorological measurement of surface fluxes. Journal of Atmospheric and Oceanic Technology 11, 1018-1025.

Humes, K.S., Kustas, W.P., Moran, M.S., 1994. Use of remote sensing and reference site measurements to estimate instantaneous surface energy balance 
components over a semiarid rangeland watershed. Water Resources Research $30,1363-1373$.

Koster, R.D., Suárez, M.J., 1992. Modeling the land surface boundary in climate models as a composite of independent vegetation stands. Journal of Geophysical Research 97, 2697-2715.

Kustas, W.P., Goodrich, D.C., 1994. Preface. Water Resources Research 30, 12111225.

Kustas, W.P., Daughtry, C.S.T., Van Oevelen, P.J., 1993. Analytical treatment of the relationships between soil heat flux/net radiation ratio and vegetation indices. Remote Sensing of Environment 46, 319-330.

Lhomme, J.P., Chehbouni, A., Monteny, B., 1994. Effective parameters of surface energy balance in heterogeneous landscape. Boundary-Layer Meteorology 71, 297-309.

Mecikalski, J.R., Diak, G.R., Anderson, M.C., Norman, J.M., 1999. Estimating fluxes on continental scales using remotely sensed data in an atmospheric-land exchange model. Journal of Applied Meteorology 38, 1352-1369.

Meijninger, W.M.L., Moene, A., Hartogensis, O., De Bruin, H.A.R., 2000. User Manual and Technical Information to the Large Aperture Scintillometer. Wageningen University, The Netherlands.

Meijninger, W.M.L., Green, A.E., Hartogensis, O.K., Kohsiek, W., Hoedjes, J.C.B., Zuurbier, R.M., De Bruin, H.A.R., 2002a. Determination of area-averaged water vapour fluxes with a large aperture and radio wave scintillometers over a heterogeneous surface-flevoland field experiment. Boundary-Layer Meteorology 105, 63-83.

Meijninger, W.M.L., Hartogensis, O.K., Kohsiek, W., Hoedjes, J.C.B., Zuurbier, R.M., De Bruin, H.A.R., 2002b. Determination of area-averaged sensible heat fluxes with a large aperture scintillometer over a heterogeneous surface - Flevoland field experiment. Boundary-Layer Meteorology 105, 37-62.

Meijninger, W.M.L., Beyrich, F., Lüdi, A., Kohsiek, W., De Bruin, H.A.R., 2006. Scintillometer-based turbulent fluxes of sensible and latent heat over a heterogeneous land surface - a contribution to Litfass-2003. Boundary-Layer Meteorology 121, 89-110.

Moene, A.F., 2003. Effects of water vapour on the structure parameter of the refractive index for near-infrared radiation. Boundary-Layer Meteorology 107, 635-653.

Monteith, J.L., Unsworth, M.H., 1990. Principles of Environmental Physics. Edward Arnold, London.

Moore, C.J., 1986. Frequency response corrections for eddy correlation systems. Boundary-Layer Meteorology 37, 17-35.

Moran, M.S., Kustas, W.P., Vidal, A., Stannard, D.I., Blanford, J.H., Nicholas, W.D., 1994. Use of ground-based remotely sensed data for surface energy balance evaluation of a semiarid rangeland. Water Resources Research 30, 13391349.

Mu, Q., Heinsch, F.A., Zhao, M., Running, S.W., 2007. Development of a global evapotranspiration algorithm based on MODIS and global meteorology data. Remote Sensing of Environment 111 (4), 519-536.

Noilhan, J., Lacarrere, L., 1995. GCM grid scale evaporation from mesoscale modelling: a method based on parameter aggregation tested for clear days of Hapex-Mobilhy. Journal of Climate 8, 206-223.

Noilhan, J., Lacarrere, P., Dolman, A.J., Blyth, E.M., 1997. Defining area-average parameters in meteorological models for land surfaces with mesoscale heterogeneity. Journal of Hydrology 190, 302-316.

Norman, J.M., Kustas, W.P., Humes, K.S., 1995. A two-source approach for estimating soil and vegetation energy fluxes from observations of directional radiometric surface temperature. Agriculture and Forest Meteorology 77, 263-293.

Norman, J.M., Kustas, J., Prueger, H., Diak, G.R., 2000. Surface flux estimation using radiometric temperature: a dual-temperature-difference method to minimize measurement errors. Water Resources Research 36, 2263-2274.
Norman, J.M., Anderson, M.C., Kustas, W.P., French, A.N., Mecikalski, J., Torn, R., Diak, G.R., Schmugge, J.J., Tanner, B.C.W., 2003. Remote sensing of surface energy fluxes at $10^{1}-\mathrm{m}$ pixel resolutions. Water Resource Research 39 (8), 1221. doi:10.1029/2002WR00177.

Ochs, G.R., Wilson, J.J., 1993. A second-generation large-aperture scintillometer, vol. 177. NOAA Tech. Memo, ERL WPL-232, NOAA Environmental Research Laboratories, Boulder, Co. Publ., pp. 117-132.

Ortega Farías, S., Antonioletti, R., Olioso, A., 2000. Net radiation model evolution at an hourly time step for Mediterranean conditions. Agronomie 20,157-164.

Panofsky, H.A., Dutton, J.A., 1984. Atmospheric Turbulence. Models and Methods for Engineering Applications. John Wiley \& Sons, New York.

Peugeot, C., Cappelaere, B., Vieux, B.E., Séguis, L., Maia, A., 2003. Hydrologic process simulation of a semiarid, endoreic catchment in Sahelian West Niger. 1. Modelaided data analysis and screening. Journal of Hydrology 279, 224-243.

Ramier, D., Boulain, N., Cappelaere, B., Timouk, F., Boubkraoui, S., Metayer, F., Lloyd C., Descroix, L., this issue. Towards an understanding of coupled physical and biological processes in central sahel -1 . Energy and water.

Raupach, M.R., Finnigan, J.J., 1995. Scale issues in boundary-layer meteorology: surface energy balances in heterogeneous terrain. Hydrological Processes 9 , 589-612.

Santanello, J.A., Friedl, M.A., 2003. Diurnal covariation in soil heat flux and net radiation. Journal of Applied Meteorology 42 (6), 851-862.

Schmugge, J.T., Kustas, W.P., Humes, S.K., 1998. Monitoring land surface fluxes using aster observations. IEEE Transactions on Geoscience and Remote Sensing 36 1421-1430.

Schotanus, P., Nieuwstadt, F., De Bruin, H.A.R., 1983. Temperature measurement with a sonic anemometer and its application to heat and moisture fluxes. Boundary-Layer Meteorology 26, 81-93.

Sellers, P.J., Heiser, M.D., Hall, F.G., Verma, S.B., Desjardins, R.L., Schuepp, P.M., MacPherson, J.I., 1997. The impact of using area-averaged land surface properties - topography, vegetation condition, soil wetness - in calculations of intermediate scale (approximately $10 \mathrm{~km}^{2}$ ) surface-atmosphere heat and moisture fluxes. Journal of Hydrology 190, 269-301.

Shuttleworth, W.J., Yang, Z.L., Arain, M.A., 1997. Aggregation rules for surface parameters in global models. Hydrology and Earth System Sciences 2, 217-226.

Su, Z., 2002. The surface energy balance system (SEBS) for estimation of turbulent heat fluxes. Hydrology and Earth System Sciences 6, 85-99.

Timmermans, W.J., Kustas, W.P., Anderson, M.C., French, A.N., 2007. An intercomparison of the surface energy balance algorithm for land (SEBAL) and the two-source energy balance (TSEB) modeling schemes. Remote Sensing of Environment 108, 369-384.

Twine, T.E., Kustas, W.P., Norman, J.M., Cook, D.R., Houser, P.R., Meyers, T.P. Prueger, J.H., Starks, P.J., Wesley, M.L., 2000. Correcting eddy-covariance flux underestimates over a grassland. Agriculture and Forest Meteorology 103, 279300.

Van Dijk, A., Kohsiek, W., De Bruin, H.A.R., 2003. Oxygen sensitivity of krypton and lymann - a hygrometers. Journal of Atmospheric and Oceanic Technology 20 143-151.

Webb, E.K., Pearman, G.I., Leuning, R., 1980. Correction of flux measurements for density effects due to heat and water vapour transfer. Quarterly Journal of the Royal Meteorological Society 106, 85-100.

Wesely, M.L., 1976. The combined effect of temperature and humidity fluctuations on refractive index. Journal of Applied Meteorology 15, 43-49.

Wilczak, J., Oncley, S., Stage, S.A., 2001. Sonic anemometer tilt correction algorithms. Boundary-Layer Meteorology 99, 127-150.

Zhan, X., Kustas, W.P., Humes, K.S., 1996. An intercomparison study on models of sensible heat flux over partial canopy surfaces with remotely sensed surface temperature. Remote Sensing of Environment 58, 242-256. 